\title{
Learning new meanings for old words: effects of semantic relatedness
}

\author{
Jennifer M. Rodd • Richard Berriman • Matt Landau • \\ Theresa Lee • Carol Ho • M. Gareth Gaskell • \\ Matthew H. Davis
}

Published online: 22 May 2012

(C) Psychonomic Society, Inc. 2012

\begin{abstract}
Changes to our everyday activities mean that adult language users need to learn new meanings for previously unambiguous words. For example, we need to learn that a "tweet" is not only the sound a bird makes, but also a short message on a social networking site. In these experiments, adult participants learned new fictional meanings for words with a single dominant meaning (e.g., "ant") by reading paragraphs that described these novel meanings. Explicit recall of these meanings was significantly better when there was a strong semantic relationship between the novel meaning and the existing meaning. This relatedness effect emerged after relatively brief exposure to the meanings (Experiment 1), but it persisted when training was extended across 7 days (Experiment 2) and when semantically demanding tasks were used during this extended training (Experiment 3). A lexical decision task was used to assess the impact of learning on online recognition. In Experiment 3, participants responded more quickly to words whose new meaning was semantically related than to those with an unrelated meaning. This result is consistent with
\end{abstract}

Electronic supplementary material The online version of this article (doi:10.3758/s13421-012-0209-1) contains supplementary material, which is available to authorized users.

J. M. Rodd $(\varangle) \cdot$ R. Berriman $\cdot$ M. Landau $\cdot$ T. Lee $\cdot$ C. Ho Research Department of Cognitive Perceptual and Brain Sciences, University College London,

London, UK

e-mail: j.rodd@ucl.ac.uk

M. G. Gaskell

Department of Psychology, University of York,

York, UK

M. H. Davis

MRC Cognition and Brain Sciences Unit,

Cambridge, UK earlier studies showing an effect of meaning relatedness on lexical decision, and it indicates that these newly acquired meanings become integrated with participants' preexisting knowledge about the meanings of words.

Keywords Semantic ambiguity $\cdot$ Language acquisition . Word learning $\cdot$ Semantic priming $\cdot$ Lexical ambiguity

\section{Introduction}

Adults often need to learn new meanings for words that are already well established in their mental lexicon. This phenomenon can be driven by changes in the language itself, with new word meanings emerging to keep up with new technologies (Blank, 1999). For example, the development of computers required adults to learn new meanings for the words "mouse," "window," "virus," "web," and so forth. More recently, social networking websites have resulted in new, highly specific meanings for the verbs to "friend," to "post," and to "tweet." Adults may also learn new word meanings when they join a new social, academic, or geographical community. For example, someone taking up rowing would need to learn new meanings for the words "catch," "square," and "feather," while students of statistics must learn specific new meanings for the words "variable," "dependent," "normal," and "significant."

One important characteristic of these new word meanings is that they are often semantically related to the existing meanings of the words, in terms of their physical properties (e.g., "mouse"), function (e.g., "virus"), or other conceptual properties. This form of ambiguity between semantically related word senses is also ubiquitous in the existing meanings of words. For example, the word "run" has up to 35 different related senses (e.g., "the athlete runs the race," "the 
politician runs for election," or "the car runs on petrol"; Parks, Ray, \& Bland, 1998). Thus, when learning a new sense for an existing word, people add to their already extensive repertoires of words for which they know multiple different senses. This form of ambiguity between related word senses (polysemy) can be contrasted with homonymy, in which, due to a historical accident, a single word form corresponds to multiple unrelated meanings (e.g., "tree bark" vs. "dog's bark"). This form of semantic ambiguity is far less common than polysemy (Rodd, Gaskell, \& Marslen-Wilson, 2002) and may correspond to new meanings that are only loosely related to the original meaningfor example, "google" (or "googol") originally referred to the number $1 \times 10^{100}$, which has no obvious or transparent relationship to searching for information on the Internet.

Existing studies looking at how adults learn about ambiguous words have shown that adults are highly skilled at working out the meanings of novel word senses (Clark and Gerrig 1983; Frisson and Pickering 2007) and at adjusting their preferences for known word meanings (Rodd, Lopez Cutrin, Millar, \& Davis, 2012). However, despite the numerous everyday examples illustrated above, we are unaware of any studies that have looked at how adults learn new meanings for words that they already know. In the experiments reported here, we used a new experimental method to study this aspect of word learning and, in particular, to explore the role of the semantic relationship between the existing and novel meanings.

In these experiments, words with a single dominant meaning (e.g., "ant") were embedded within paragraph contexts that described a new fictional meaning, which was either semantically related or unrelated to the word's original meaning. The length and the nature of the training were varied across experiments. Participants' knowledge about these word meanings was then assessed using two tasks. A cued-recall memory test assessed their explicit knowledge about the novel meanings (Exps. 1-3), and a lexical decision task assessed whether these new meanings had become sufficiently well learned that they could affect online speeded recognition of these words (Exps. 2 and 3).

For the cued-recall task, we predicted that participants would recall more properties for the semantically "related" meanings than for the semantically "unrelated" meanings. For related meanings, the previously familiar mapping between the form of a word and its existing meaning could act as a retrieval cue to help the learner remember which form to associate with the new meaning.

This relatedness effect is also predicted by a connectionist model (Rodd, Gaskell, \& Marslen-Wilson, 2004), which was put forward to explain such effects in previous lexical decision experiments. Although the effect remains controversial (see Lupker, 2007, for a detailed review), several experiments have shown that whereas lexical decisions to words with multiple unrelated meanings (e.g., "bark") are slower than those to equivalent unambiguous items, words with numerous related word senses (e.g., "run") are recognised more quickly than unambiguous items (Beretta, Fiorentino, \& Poeppel, 2005; Klepousniotou, Titone, \& Romero, 2008; Rodd, 2004; Rodd et al. 2002). The Rodd et al. (2004) model characterises word recognition as a process by which distributed representations of word forms are mapped onto distributed representations of meaning (semantics). A key property of this model is that it uses interaction within the semantic units (using recurrent connections) to "clean up" any pattern of semantic activation projected onto those units. For a word with multiple unrelated meanings (e.g., "bark"), a blend (or mixture) of its two meanings is initially activated, and the connections between the semantic units then "clean up" this activation to ensure that the network settles into a pattern of activation reflecting one of the known meanings of that word. It is this additional "cleaning up" process that delays recognition relative to unambiguous words. In contrast, the multiple related senses of words like "run" correspond to highly overlapping distributed representations, and a meaningful and stable representation can be activated rapidly. Indeed, simulations demonstrated that recognition of such words is facilitated (relative to unambiguous words) because their flexible meanings correspond to a larger area within the space of possible semantic representations. Importantly, within this model, issues of processing and acquisition cannot be dissociated, so any variable that influences processing should also influence learning. Under this view, unrelated meanings both should be harder to learn and, once learned, should be slower to recognise. This model therefore predicts that an effect of relatedness should be present at all stages of learning new word meanings and should be seen on both the cued-recall task and the lexical decision task.

An alternative outcome is that semantic relatedness will influence performance on the cued-recall task but will not influence lexical decision performance. Recent studies of word form learning have shown that the initial acquisition of knowledge about words can sometimes be dissociated from the subsequent consolidation of this knowledge into the lexicon: Although new word forms can be rapidly learned after a few presentations, this knowledge does not interact with preexisting lexical representations until after consolidation has taken place. For example, the rapid learning of the novel phonological word form "cathedruke" can be dissociated from the subsequent impact of this knowledge on participants' ability to recognise the existing word "cathedral" (Dumay and Gaskell, 2007; Gaskell and Dumay, 2003). This idea is closely related to the distinction drawn by Leach and Samuel, (2007) between "lexical configuration" and "lexical engagement." While the former term refers to the acquisition of the "set of factual knowledge 
associated with a word" (e.g., its sound, spelling, or meaning), the latter refers to the ability of a word to dynamically interact with other linguistic representations. If information about the words' new meanings is learned without being integrated with existing lexical knowledge, then participants' lexical decisions will be made solely on the basis of their preexisting lexical representation of the word's primary meaning without any influence of the newly acquired meaning, and will therefore show no effect of meaning relatedness. One plausible outcome would be that the presence of a relatedness effect on lexical decision performance may critically depend on the nature of a participant's experience with these words during training, such that this effect only emerges once training has been sufficiently extensive to allow the new meanings to become integrated with preexisting lexical representations.

In addition, it is important to emphasise that the effect of semantic relatedness in lexical decision tasks remains contentious. While several authors have reported such effects (Azuma and Van Orden, 1997; Beretta et al. 2005; Klepousniotou et al. 2008; Rodd, 2004; Rodd et al. 2002), as with all experiments that compare sets of words that are selected to differ on one critical psycholinguistic property, it is difficult to ensure that these sets are well matched on other important variables. The natural correlation between ambiguity and variables such as word frequency, age of acquisition, and neighbourhood size makes this issue particularly challenging. Indeed, some lexical decision experiments have failed to replicate the effect of meaning relatedness (e.g., Hino, Kusunose, \& Lupker, 2010). The present lexical decision experiments will attempt to replicate the relatedness effect using a within-item design; this result could only be achieved by artificially modifying participants' knowledge of words and their meanings (cf. Bowers, Davis, \& Hanley, 2005; Gaskell and Dumay, 2003).

In summary, these experiments will explore (1) the impact of semantic relatedness on people's ability to learn new meanings, (2) the time course with which new word meanings can become sufficiently well integrated into the lexicon to affect online comprehension, and (3) whether previously reported semantic-relatedness effects on lexical decision can be replicated in a within-item design that could artificially modify participants' knowledge of words and their meanings.

\section{Experiment 1}

The experiment consisted of three parts that took place within a single testing session: (1) a rating task, in which participants read the training paragraphs and rated their novelty, plausibility, and clarity; (2) a test of general vocabulary; and (3) a cued-recall test, in which participants recalled as many pieces of information as possible about the meanings described in the training paragraphs.

\section{Method}

\section{Participants}

The 22 participants (15 female, 7 male; 20-34 years of age) were members of the University College London (UCL) Psychology Participant Pool and were monolingual native English speakers with normal or corrected-to-normal vision. They were paid for their participation.

\section{Stimuli and design}

The 36 target words (see Table 1 and the Appendix) had only one entry in the Wordsmyth dictionary (Parks et al. 1998). A paragraph was created for each word that described a new noun meaning that was semantically related to the word's existing meaning (see the supplemental materials). The new meanings were designed to be semantically diverse and to consist of new innovations $(n=7)$, features of the natural world $(n=5)$, social phenomena/traditions $(n=6)$, technical terms $(n=13)$, invented objects $(n=3)$, and colloquial terms $(n=2)$. The new meanings were related to the old meanings in terms of their physical properties (e.g., size or colour; $n=14$ ), function $(n=5)$, being a specific variant of a more general meaning $(n=8)$, or the imagery that the word elicited (e.g., HIVE as a busy household; $n=8$ ). The paragraphs (86-94 words) included the target word five times and contained five different pieces of information about the new meaning that were not true for the existing meaning. The set of unrelatedmeaning paragraphs were created by swapping the paragraphs across pairs of target words. These pairings were chosen to ensure minimal overlap between the related and unrelated meanings for each word.

To ensure that participants would see each target word and each paragraph only once, but that each word-paragraph combination would be seen at least once across participants, two versions of the experiment were created that each contained 18 paragraphs with a new related meaning and 18 with a new unrelated meaning. The words presented in a related paragraph in Version 1 were presented in an unrelated paragraph in Version 2, and vice versa. Half of the participants (randomly selected) saw each version.

\section{Procedure}

The stimuli for this (and all subsequent computer-based experiments) were presented using E-Prime (Schneider, Eschman, \& Zuccolotto, 2002). The participants took short breaks between the parts of the experiment. 
Table 1 Descriptive statistics of the target words

\begin{tabular}{llllllllll}
\hline & $N$ & $\begin{array}{l}\text { CELEX } \\
\text { Frequency (Raw) }\end{array}$ & $\begin{array}{l}\text { CELEX Frequency } \\
\text { (Log-Transf.) }\end{array}$ & $\begin{array}{l}\text { Orthographic } \\
\text { Neighbours }\end{array}$ & Syllables & $\begin{array}{l}\text { WordNet } \\
\text { Senses }\end{array}$ & $\begin{array}{l}\text { WordSmyth } \\
\text { Senses }\end{array}$ & $\begin{array}{l}\text { ELP Lexical } \\
\text { Decision RT }\end{array}$ & $\begin{array}{l}\text { ELP Lexical } \\
\text { Decision } \\
\text { Accuracy }\end{array}$ \\
\hline Trained words & 36 & 27.2 & 2.98 & 8.64 & 1.08 & 4.58 & 4.97 & 629 & 0.95 \\
Untrained words & 72 & 26.8 & 2.93 & 8.31 & 1.10 & 4.46 & 5.07 & 633 & 0.96 \\
\hline
\end{tabular}

Trained words were used in Experiments 1-3. Untrained words were only included in the lexical decision task in Experiments 2 and 3. Sense counts come from WordNet (Fellbaum, 1998) and WordSmyth (Parks et al. 1998). "ELP lexical decision" performance refers to the results obtained within the English Lexicon Project (Balota et al. 2007). RT, response time

Rating task The participants were instructed to carefully read a series of paragraphs that contained new, fictitious meanings for words that they already knew. The paragraphs appeared one at a time in the top half of the screen. Once a participant pressed the space bar to indicate that the reading was finished, three questions appeared (one at a time) in the bottom half of the screen: "How novel do you think this new meaning is?," "How plausible do you think it is that the word would be used in this context?," and "How clear do you think this paragraph is?" Participants responded on a 7point Likert scale from 1 to 7 using the keyboard. After making these responses, a blank screen was presented for $300 \mathrm{~ms}$ before the next paragraph appeared. To ensure that participants spent enough time reading, each paragraph appeared for at least $10 \mathrm{~s}$ before the rating task could begin. The presentation order was randomised for each participant. In order to mimic as closely as possible the type of incidental learning that occurs during natural vocabulary acquisition, the participants were not told to try to remember the new meanings and were not told that their memory would subsequently be tested.

Vocabulary test The participants completed a computerized version of a 34-item vocabulary test (Mill Hill Vocabulary Test, Set A: Multiple Choice: Buckner et al. 1996; Raven, Raven, \& Court, 1998). For each item on the test, they were to select the word with the meaning closest to that of the word, from a list of six options. This task served as a short filler between the training and test phases of the experiment. ${ }^{1}$ The vocabulary test did not include any of the target words.

Cued-recall test Each word appeared on the screen in isolation, and the participants were asked to type all of the properties that they could recall into a text box with the numbers 1-9 running down the left-hand side. They were told only to give properties of the new meaning and were

\footnotetext{
${ }^{1}$ It was hoped that this test would also allow us to assess the relationship between participants' learning performance and their existing vocabulary size, but these results were of limited interest and will not be reported.
}

encouraged to remember as much as possible. If they could not recall any information, they were instructed to type "cannot remember." After pressing the control button to indicate that they had completed that item, a blank screen was presented for $300 \mathrm{~ms}$ before the next word appeared. The presentation order was randomized (without constraints) for each participant.

\section{Results}

\section{Rating task}

Participants made ratings of novelty, plausibility, and clarity for each of the related and unrelated paragraphs (Table 2). A set of $2 \times 2$ repeated measures ANOVAs were conducted on the participant and item means, with the factors Relatedness and Version. Throughout this report, main effects and interactions involving Version are not reported (Pollatsek and Well, 1995). The related paragraphs were rated as significantly less novel $\left[F_{1}(1,20)=18.7, p<.001 ; F_{2}(1,34)=\right.$ $90.3 p<.001]$, more plausible $\left[F_{1}(1,20)=91.8, p<.001\right.$; $\left.F_{2}(1,34)=82.9, p<.001\right]$, and more clear $\left[F_{1}(1,20)=\right.$ $\left.26.6, p<.001 ; F_{2}(1,34)=47.6, p<.001\right]$ than the unrelated paragraphs.

\section{Cued-recall test}

Responses were independently marked by two judges and were allocated one mark for each of the five properties that were correctly recalled. There was $85.5 \%$ agreement between the judges over the 792 responses, and discrepancies were resolved by discussion. In a small proportion of cases

Table 2 Experiment 1: Results of the rating task (calculated across participants)

\begin{tabular}{|c|c|c|c|c|c|c|}
\hline & \multicolumn{2}{|l|}{ Novelty } & \multicolumn{2}{|c|}{ Plausibility } & \multicolumn{2}{|l|}{ Clarity } \\
\hline & Related & Unrelated & Related & Unrelated & Related & Unrelated \\
\hline Mean & 3.97 & 5.06 & 4.88 & 3.16 & 5.69 & 5.06 \\
\hline St Dev. & 0.99 & 1.31 & 0.85 & 0.84 & 0.92 & 0.96 \\
\hline
\end{tabular}


( $n=20,2.5 \%)$ no clear resolution could be reached, and the average of the two marks was awarded. A response to any given word was considered to be "correct" if at least one property was correctly recalled. The numbers of paragraphs for which a "correct" response was given ranged (across participants) from 3 to 26 of the 36 paragraphs (mean = 17.23, $S D=7.27$ ). A set of $2 \times 2$ repeated measures ANOVAs were conducted on the participant and item means, with the factor of Relatedness (related or unrelated) measured within subjects/items and Version measured between subjects/items.

The proportion of correct responses was significantly higher for related than for unrelated paragraphs [Table 3; $\left.F_{1}(1,20)=172.4, p<.001 ; F_{2}(1,34)=152.8 p<.001\right]$. Because of the large proportion of unrelated trials on which no information was correctly recalled (74 \%), it was not possible to assess whether (for those items that were correctly recalled) more information was recalled for related than for unrelated paragraphs.

To assess whether memory performance was related to participants' ratings of novelty, plausibility, and clarity, and to assess whether the effect of Relatedness was still significant when these variables were taken into account, an ANCOVA was conducted using the item means, with the factors of both Relatedness and Version measured between items and the factors of Novelty, Plausibility, and Clarity included as covariates. Because each wordparagraph combination had an individual rating on each of these measures, it was necessary to use a betweenitems approach to the analysis. As with the main analysis, we found a significant effect of Relatedness on the proportions of correct responses $[F(1,65)=23.1, p<.001]$. The covariates of Novelty, Plausibility, and Clarity were nonsignificant $(p>.2)$

Table 3 Cued-recall results: Performance for the related and unrelated words (calculated across participants)

\begin{tabular}{|c|c|c|c|c|c|}
\hline & & \multicolumn{2}{|c|}{$\begin{array}{l}\text { Proportion of } \\
\text { Correct } \\
\text { Responses }\end{array}$} & \multicolumn{2}{|c|}{$\begin{array}{l}\text { Number of Properties } \\
\text { Recalled (Correct } \\
\text { Responses Only) }\end{array}$} \\
\hline & & Mean & $S D$ & Mean & $S D$ \\
\hline \multirow[t]{2}{*}{ Experiment 1} & Related & 0.70 & 0.26 & & \\
\hline & Unrelated & 0.26 & 0.15 & & \\
\hline \multirow[t]{2}{*}{ Experiment 2} & Related & 1.00 & 0.00 & 2.63 & 0.58 \\
\hline & Unrelated & 0.52 & 0.25 & 1.80 & 0.34 \\
\hline \multirow[t]{2}{*}{ Experiment 3} & Related & 0.93 & 0.11 & 3.33 & 0.58 \\
\hline & Unrelated & 0.77 & 0.24 & 3.27 & 0.57 \\
\hline
\end{tabular}

A response to a given item is classified as "correct" if a participant recalled any correct information for that item. For Experiment 1, only the data for the first variable are included due to the low number of correct responses to unrelated words
Intrusion errors (i.e., recall of incorrect information) were relatively rare ( $n=90,11.4 \%$ of the total responses). We found significantly more errors for unrelated words $(n=60$, $63.7 \%)$ than for related words $(n=30)$ on a binomial test $(p=.015)$. These errors consisted of three types. In a very small number of cases ( $n=6: 2$ related, 4 unrelated), the participants recalled a property related to the word's original definition (e.g., recalling PEARL as a jewel). Transfer errors (i.e., recalling a property from another novel definition) were slightly more common ( $n=24,26.7 \%$ of errors) and were significantly more common for unrelated paragraphs $(n=20,83.3 \%)$ than for related paragraphs $(n=4)$ on a binomial test $(p=.002)$. The remaining "semantic" errors $(n=60,66.67 \%$ of errors) consisted of responses that were incorrect for both the original and the new word meanings and that were also not correct for any other paragraph that was used in the experiment (e.g., remembering PATH as a tattoo rather than as face paint or CREW as musicians rather than singers). These errors were slightly more common for unrelated paragraphs (55\%), but this difference this was not significant on a binomial test $(p=.519)$.

\section{Discussion}

This experiment showed that the participants' ability to recall new meanings for familiar words was significantly better for meanings that were semantically related to the existing meaning than for unrelated meanings. This relatedness effect was strikingly large: Participants were only able to recall some correct information for $26 \%$ of unrelated items, as compared with $70 \%$ of the related meanings. This indicates that the presence of a semantic relationship between the "old" and "new" meanings strongly facilitates the learning of the mapping between form and meaning. Due to the low level of performance on the unrelated meanings, it was not possible to assess whether relatedness also affects the richness of the newly acquired semantic representation. This issue needed to be addressed in an experiment in which the participants would achieve better overall performance in learning novel unrelated meanings of existing words.

\section{Experiment 2}

The primary aim of this experiment was to investigate the effects of meaning relatedness beyond a single learning episode by extending the learning phase across a 6-day period and by introducing a delay of approximately $24 \mathrm{~h}$ between the final training session and the testing phase. This procedure allowed us to assess whether previously poor acquisition of unrelated new meanings would be improved by more extended learning and to determine whether the 
strong effect of relatedness seen in Experiment 1 would become more or less pronounced with time.

A second aim of the experiment related to the effect of semantic relatedness on the quality of the newly learned semantic representations. In Experiment 1, this analysis had not been possible due to the low number of unrelated paragraphs for which any information was recalled. By extending the learning period, it was expected that performance would be sufficiently improved that we could explore this important effect in more detail.

The third aim was to use an additional lexical decision task to assess whether the new meanings had become sufficiently well learned that they could impact on an online speeded task in which there was no requirement for the new meaning to play a role. Experiment 1 had shown that participants are able to retain some information about new word meanings relatively rapidly, but the explicit memory task that was used could not reveal whether this information had become integrated with existing lexical knowledge about the word's primary meaning. From previous studies of semantic ambiguity (Beretta et al. 2005; Klepousniotou et al. 2008; Rodd et al. 2002), if lexical integration has occurred, then we should see a benefit for the words whose new meaning was semantically related to the existing meaning, as compared with words with an unrelated new meaning. In contrast, if no such integration has occurred, then participants' speeded responses to these highly familiar words would be unaffected by the semantic-relatedness variable.

\section{Method}

\section{Participants}

The 15 participants (six female, nine male; 19-32 years of age) were members of the UCL Psychology Participant Pool and were monolingual native English speakers with normal or corrected-to-normal vision. They were paid for their participation.

\section{Stimuli and design}

The target words, paragraphs, and assignment of items to versions were the same as in Experiment 1. The paragraphs were included in printed booklets that could be taken home by the participants. Each page of the booklet contained just one paragraph. For each version of the booklet, two presentation orders were created. The four possible combinations of version and presentation order were each seen by either three or four participants. The first version was randomly generated, and the second was created by reversing the first. Six rating booklets were created, each referring to one of the following properties: novelty, plausibility, clarity, coherence, logicality, and interest. As with Experiment 1, ratings for each word or paragraph were made on a 7-point scale from low to high. To ensure that the participants read the paragraphs during the unsupervised training sessions that took place outside of the lab, six short memory tests were developed that contained 12 simple questions apiece about the meanings contained in the booklets (two questions per paragraph read during the week). Some of the questions were open ended (e.g., "Why were stubs usually killed in the past?"), and other questions required participants to fill in a blank (e.g., "__ is now considered one of the most desirable massages available.").

An additional 72 words were selected for use in the lexical decision experiment. These words, which did not appear in the training booklets or in the vocabulary test, were well matched to the training words for frequency, orthographic neighbourhood, syllable count, and number of senses, as well as for lexical decision performance in the English Lexicon Project (Balota et al. 2007; see Table 1 and the Appendix). A total of 108 pseudohomophones with a similar distribution of word length were selected from previous experiments (Rodd, 2001; Rodd et al. 2002; see the Appendix). In addition, a further 14 words and 14 nonwords with similar properties were used for the practice session, and three words and three nonwords were used as lead-in items at the start of each block of the experiment (Appendix).

\section{Procedure}

The experiment consisted of an initial lab-based learning session, five home-based learning sessions, and a final labbased test session. These sessions took place on seven consecutive days. On the first learning day, the participants were given a booklet of paragraphs and a rating booklet and were instructed to read the paragraphs one at a time and then to rate them for novelty on the 7-point scale. The participants then completed the first memory test (12 questions) without referring to the booklet. This first training day acted as an example of what to do on the next 5 days at home. The participants were instructed to complete one rating task per day (i.e., rating clarity, plausibility, coherence, interest, or logicality) at roughly the same time as the first session. The memory tests were sent to them via e-mail every day at approximately the same time, and they were required to send their answers back that day. This ensured that the training was appropriately spread across the six training days. Participants were not instructed to memorize the meanings of the words during the rating task, but they were aware that their memory for these meanings would be tested. 
On Day 7, the participants returned to the lab to submit their rating booklets and to complete the lexical decision experiment, the Mill Hill Vocabulary Test, and the cued-recall test. The lexical decision experiment was positioned at the start of this testing session to ensure that priming of the newly acquired meanings from the cued-recall test was not a possibility. The vocabulary test and explicit memory test were based on the same procedure as in Experiment 1.

In the lexical decision test, a fixation point appeared in the centre of the monitor for $500 \mathrm{~ms}$, followed by a single word. The participants indicated via keyboard responses whether each word was a real English word (1 for real word, 2 for nonword). After each response, the word was replaced by a new fixation point. The 36 trained words, 72 untrained words, and 108 pseudohomophones were divided into four blocks pseudorandomly, such that each block contained the same number from each condition. Participants saw the four blocks in a randomized order, with the additional constraint that each possible order was seen by no more than one participant. Within each block, the order of the items was randomized for each participant. A practice session consisting of 28 filler items (half words and half nonwords) was completed before the experimental blocks.

\section{Results}

Ratings task

Participants made ratings of novelty, plausibility, clarity, coherence, interest, and logicality for each paragraph (see Table 4).

\section{Memory questions}

The participants answered 12 questions on each of the 6 days of training. Overall, participants achieved $58 \%$ correct (range across participants $=39 \%-85 \%$ ).

Lexical decision

One of the 15 participants was removed due to highly variable performance across different blocks and to a high proportion of very slow responses $(S D=342 \mathrm{~ms}, 28 \%$ of responses greater than $1,000 \mathrm{~ms}$ ). The remaining participants made between $0.9 \%$ and $15.7 \%$ errors, with response times that ranged between 475 and $878 \mathrm{~ms}$. One of the trained words ("snow") was inadvertently omitted from the experiment. Also, one of the untrained words ("sled") was removed because its error rate was greater than $50 \%$. Only correct response times were included in the analyses. Individual responses that were greater than three standard deviations above the mean for that participant or shorter than $250 \mathrm{~ms}$ were excluded $(1.7 \%$ of the responses to experimental items). Analyses were conducted on response times and error rates using means that were calculated across both participants and items (Fig. 1).

The first set of ANOVAs compared the response times and error rates for the trained words (combined across levels of Relatedness) with the untrained words. Condition (trained vs. untrained) was included as a within-subjects/-items variable for the subjects and items analyses, respectively. Version was included as a between-subjects variable for the subjects analysis and as a within-items variable for the items analysis. Participants responded significantly more slowly to the untrained words than to the trained words $\left[F_{1}(1,12)=10.3, p<.01 ; F_{2}(1,104)=\right.$ $10.7, p<.001]$. The participants also made marginally more errors to the untrained words than to the trained words $\left[F_{1}(1\right.$, $\left.12)=3.6, p=.08 ; F_{2}(1,104)=3.1, p=.08\right]$.

The second set of analyses excluded the untrained words and compared the two types of trained words. Relatedness (related vs. unrelated) was included as a within-subjects/-items factor, and Version was included as a between-subjects/-items factor. There was no effect of Relatedness on response times $\left[F_{1}(1,12)=0.01, p>.9 ; F_{2}(1,33)=0.001, p>.9\right]$ or on error rates $\left[F_{1}(1,12)=1.1, p>.3 ; F_{2}(1,33)=1.2, p>.2\right]$.

Cued-recall test

Responses were coded as in Experiment 1. Two different measures of memory performance were used as dependent measures: (1) proportions of correct responses (as in Exp. 1) and (2) the numbers of properties that were recalled for these correct responses. Overall, performance was better than in Experiment 1 (see Table 3), but it remained better for the related items than for the unrelated items in terms on the proportions of correct responses $\left[F_{1}(1,13)=52.3, p<.001\right.$;

Table 4 Experiment 2: Results of the rating task for related (R) and unrelated (U) items (calculated across participants)

\begin{tabular}{|c|c|c|c|c|c|c|c|c|c|c|c|c|}
\hline & \multicolumn{2}{|c|}{ Novelty } & \multicolumn{2}{|c|}{ Plausibility } & \multicolumn{2}{|c|}{ Clarity } & \multicolumn{2}{|c|}{ Coherence } & \multicolumn{2}{|c|}{ Interest } & \multicolumn{2}{|c|}{ Logicality } \\
\hline & $\mathrm{R}$ & $\mathrm{U}$ & $\mathrm{R}$ & $\mathrm{U}$ & $\mathrm{R}$ & $\mathrm{U}$ & $\mathrm{R}$ & $\mathrm{U}$ & $\mathrm{R}$ & $\mathrm{U}$ & $\mathrm{R}$ & $\mathrm{U}$ \\
\hline Mean & 3.36 & 4.90 & 5.05 & 3.64 & 5.57 & 5.50 & 5.23 & 5.03 & 3.98 & 4.34 & 5.08 & 3.86 \\
\hline$S D$ & 0.83 & 0.72 & 0.45 & 1.23 & 0.42 & 0.35 & 0.38 & 0.48 & 0.80 & 0.62 & 0.35 & 1.44 \\
\hline
\end{tabular}



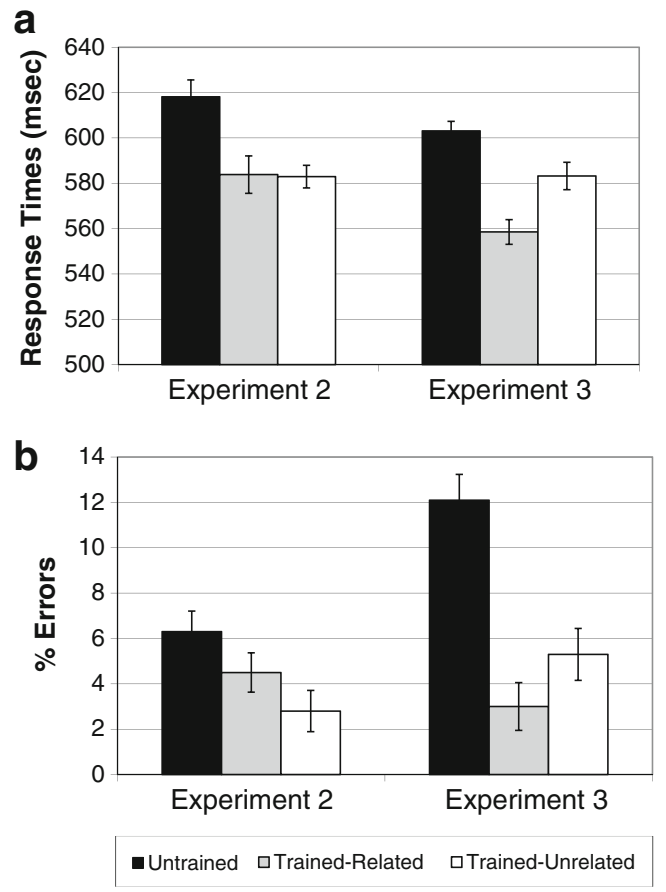

Fig. 1 Lexical decision results (Exps. 2 and 3): a Mean response times and $\mathbf{b}$ mean percentage errors for the subjects analyses. Error bars show standard errors adjusted to remove between-subjects variance

$\left.F_{2}(1,34)=200.9, p<.001\right]$ and the numbers of properties that were recalled for these correct responses ${ }^{2}\left[F_{1}(1,12)=42\right.$, $\left.p<.001 ; F_{2}(1,34)=52.5, p<.001\right]$. To explore in more detail this increase in the number of properties that were recalled, the distributions of these individual responses are shown in Fig. 2.

\section{Discussion}

In this experiment, the learning phase was extended across 6 days and participants were tested approximately $24 \mathrm{~h}$ after the final learning session, allowing us to examine longer-term memory for novel meanings. Although performance did improve relative to Experiment 1, performance on the unrelated meanings remained relatively poor. For the unrelated paragraphs, participants were only able to correctly recall some information about the word's new meaning on $52 \%$ of the trials, as compared with $100 \%$ for the related meanings. The amount of semantic information that participants could recall was also significantly lower for the unrelated meanings: For those trials on which some information was correctly recalled, participants recalled an average of 1.8 properties for the unrelated meanings, as compared with 2.6 properties for the related meanings. Meaning relatedness therefore influenced not only the likelihood of successful access to learned

\footnotetext{
${ }^{2}$ One participant was excluded from this analysis due to not recalling any correct properties for the unrelated items.
}

representations, but also the quality or amount of detail of the semantic representation that was accessed.

In contrast to this clear effect of meaning relatedness on the explicit memory test, the lexical decision task showed a different picture. Participants were faster (and marginally more accurate) to respond to words that they had seen during training, as compared to words that they had not seen during training, but this overall effect of training may merely have reflected priming of the word form. In contrast to this strong main effect of training, there was no difference between their responses to the words that they encountered during training with either a related or an unrelated meaning. This absence of a relatedness effects suggests that while participants had learned the new meanings well enough to recall in the context of an explicit memory test, this information had not become sufficiently well integrated into their lexicons that it could significantly interfere with their recognition in an online, speeded recognition task. Alternatively, it may be that meaning relatedness has only a limited impact on lexical decision responses. In the absence of sufficient learning of novel unrelated meanings, we cannot distinguish these two possibilities, so in the next experiment we sought to increase the efficacy of meaning training.

\section{Experiment 3}

In Experiments 1 and 2, the training procedure consisted of reading the paragraphs and making undemanding ratings. In both experiments, participants' ability to learn the unrelated meanings was relatively poor, and Experiment 2 showed no evidence that these meanings could influence online comprehension. In Experiment 3, we used a modified training regime that consisted of four separate worksheets that were performed separately on four consecutive days. These tasks were selected on the basis of the guidelines set out by Beck, McKeown, and Kucan (2002) and were intended to produce robust learning of the new meanings. Two of the tasks (Worksheets 1 and 3) focused explicitly on the learning of the arbitrary mapping between word form and meaning. The other two worksheets encouraged learners to deepen their semantic engagement with these new meanings (Worksheets 2 and 4).

\section{Method}

\section{Participants}

The 16 participants (two female, 14 male; $18-23$ years of age) were members of the UCL Psychology Participant Pool. Fifteen were undergraduate psychology students who participated as part of their course requirement, and the final participant (a nonpsychology undergraduate at UCL) was 
Fig. 2 Cued-recall results (Exps. 2 and 3): Distribution of the numbers of properties that were correctly recalled on each trial (as percentages of the total number of trials). Open symbols show the mean numbers of properties recalled for the correct trials a

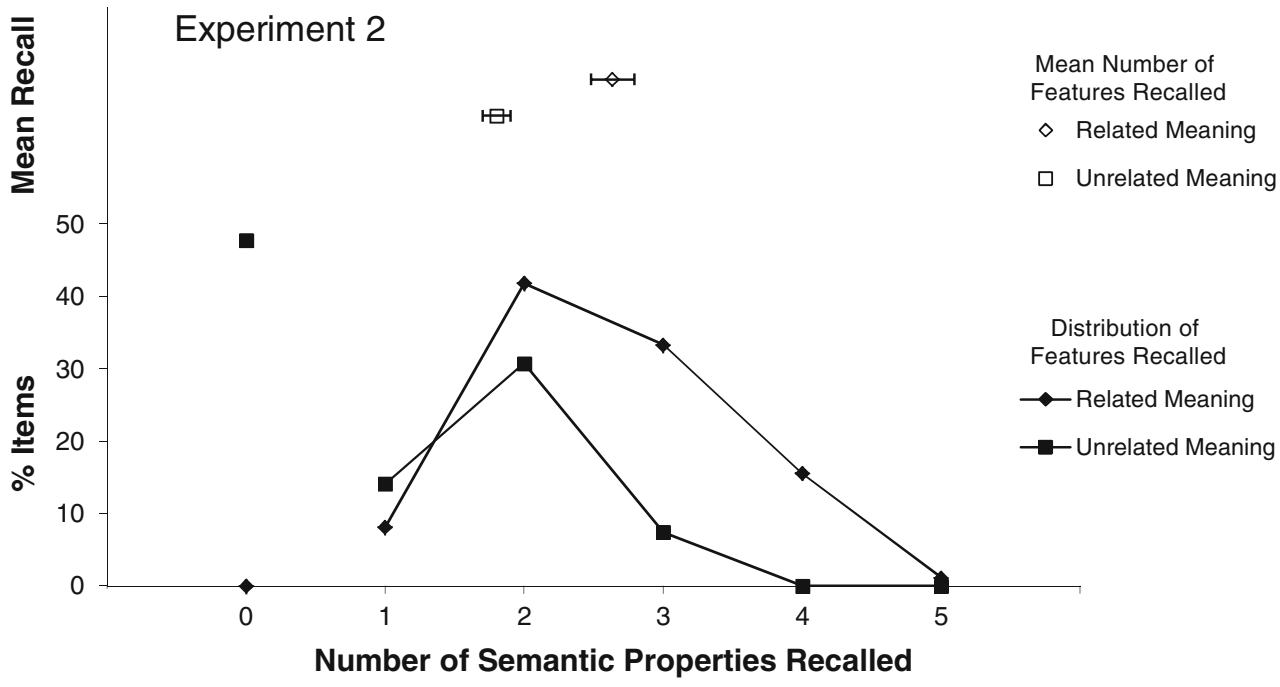

b

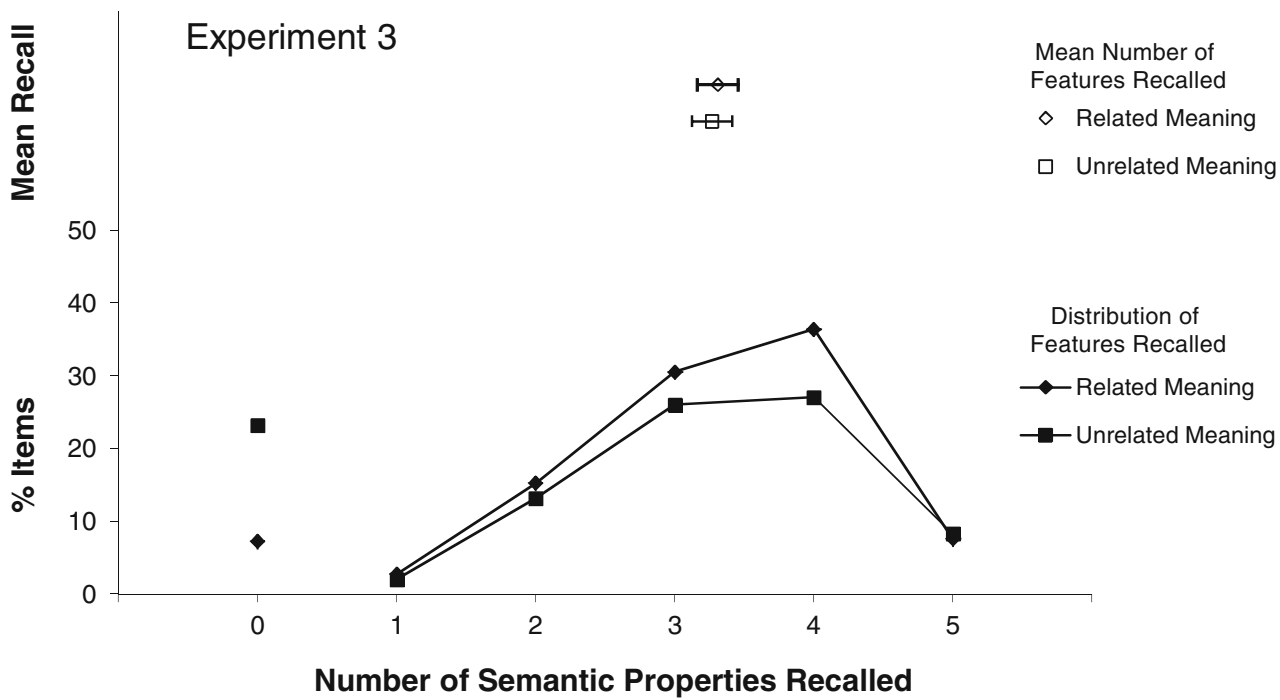

not remunerated. All were monolingual native English speakers with normal or corrected-to-normal vision. The participants were pseudorandomly assigned to the two versions and two presentation orders for the booklets.

\section{Stimuli}

The target words, paragraphs, and assignment of items to versions and presentation orders (within the training booklets) were the same as in Experiments 1 and 2. The printed booklets containing the paragraphs were identical to those used in Experiment 2. Four worksheets were also devised for use during the training phase of the experiment. Each worksheet was designed to take approximately 30-45 $\mathrm{min}$ to complete. The order of the target words was randomized separately for each worksheet. For Worksheets 1 and 3, the participants were instructed to initially fill in as much as possible without the booklet, and then to refer to the booklet to complete any answers that they did not know. For Worksheets 2 and 4, they were instructed to use the booklet throughout the task.

Worksheet 1 This two-page booklet contained a numbered list of the 36 target words, in a column on the left side, and a separate list of descriptions of the meanings of these words (e.g., "Country that exports goods at low cost"), in a column on the right side. The participants' task was to link each description with the appropriate word by writing down the appropriate number next to each description.

Worksheet 2 The participants here generated a new example sentence for each target word that was compatible with its new definition. 
Worksheet 3 The third worksheet comprised a series of quiz questions about the paragraph (two questions per word; e.g., "Where is a pouch normally found?").

Worksheet 4 The final worksheet was a creative writing task. Participants were given a list of the 36 target words and were instructed to "tell a story" that included each of these words, at least once, using their new meanings. They could write as many sentences as they liked and could write in any style and on any subject.

\section{Procedure}

On Day 1, the participants came into the lab and read through the whole booklet of word meanings and completed Worksheet 1 . The participants were then given the booklet of paragraphs to take home, together with Worksheets 2-4. They were instructed to complete one of these worksheets, in the correct order, on each of the next three consecutive days (Days 2-4) at home and in a quiet environment. Each worksheet was preceded by clear instructions, and we made clear that the participants should only read the paragraphs when directed to by the instructions. On Day 5, the participants returned to the lab and completed the lexical decision task, the vocabulary test, and the explicit memory test. The procedure for these was the same as in Experiment 2. The participants were aware that their memory for the meanings would be tested.

\section{Results}

\section{Worksheets}

Performance for the related and unrelated meanings is summarized in Table 5. For Worksheet 1, this score reflects the number of items that were correctly linked to their new meaning. For Worksheets 2 and 4, the scores reflect the numbers of items that were used appropriately within the new sentence/paragraph context. For Worksheet 3, the scores reflect the percentages of questions that were answered correctly. For Worksheets $2-4$, the answers were

Table 5 Experiment 3: Worksheet results (percentages correct)

\begin{tabular}{llllllllll}
\hline & \multicolumn{1}{l}{ Worksheet 1 } & \multicolumn{2}{l}{ Worksheet 2 } & \multicolumn{2}{l}{ Worksheet 3 } & \multicolumn{2}{l}{ Worksheet 4 } \\
\hline Condition & Mean & $S D$ & Mean & $S D$ & Mean & $S D$ & Mean & $S D$ \\
Related & 79.4 & 13.7 & 99.6 & 1.5 & 86.4 & 9.4 & 94.7 & 6.9 \\
Unrelated & 62.4 & 17.3 & 98.3 & 5.6 & 86.1 & 10.5 & 93.0 & 11.6 \\
\hline
\end{tabular}

considered correct if they matched the intended meaning in any way, even if they were lacking detail. For Worksheets 2 and 4, the participants were allowed free access to the booklets, and so would be expected to be at ceiling. No effect of Relatedness was expected on these worksheets. For Worksheets 1 and 3, the participants were encouraged to first try the task without the booklet, and so, on the basis of the results of Experiments 1 and 2, we predicted better performance for the related items. Note that these results come from worksheets that were completed outside of the lab, so we cannot be certain that all participants followed the rules exactly.

Repeated measures ANOVAs were performed on the percentage correct data for each worksheet, averaged across both items and participants. Semantic Relatedness was entered as a within-subjects factor, and Version was entered as a between-subjects factor. For Worksheet 1, participants performed significantly better for semantically related than for unrelated words $\left[F_{1}(1,34)=14.953, p<.001 ; F_{2}(1,14)=\right.$ $15.283, p<.01]$. In contrast, there were no effects of Relatedness on Worksheet $2\left[F_{1}(1,34)=2.776, p>.05 ; F_{2}(1,14)=\right.$ $0.855, p>.05]$, Worksheet $3\left[F_{1}(1,34)=0.008, p>.05 ; F_{2}(1\right.$, $14)=0.027, p>.05]$, or Worksheet $4\left[F_{1}(1,34)=0.499\right.$, $\left.p>.05 ; F_{2}(1,14)=0.517, p>.05\right]$.

\section{Lexical decision task}

One participant was removed due to highly variable response times and an unusually high proportion of very slow responses $(S D=344,19 \%$ of responses greater than $1,000 \mathrm{~ms}$ ). The remaining 15 participants made between $1.7 \%$ and $15.4 \%$ errors, with mean response times that ranged between 535 and $863 \mathrm{~ms}$. One of the trained words ("snow") was inadvertently omitted from the experiment, and two of the untrained words ("whack" and "gulp") were removed because of error rates greater than $50 \%$. Only correct response times were included in the analyses. Individual responses that were greater than three standard deviations above the mean for the participant or shorter than $250 \mathrm{~ms}$ were excluded from the analysis $(1.5 \%$ of the responses to the experimental items).

The same analyses were conducted as in Experiment 2 (see Fig. 1). Responses to the trained words were both faster $\left[F_{1}(1,13)=36.9, p<.001 ; F_{2}(1,103)=19.2, p<.001\right]$ and more accurate $\left[F_{1}(1,13)=20.0, p<.001 ; F_{2}(1,103)=10.2\right.$, $p=<.005]$ as compared with those for the untrained words. Within the set of trained items, response times were significantly faster for the related than for the unrelated words $\left[F_{1}(1,13)=4.9, p<.05 ; F_{2}(1,33)=7.5, p<.01\right]$. Participants were more accurate for the related words, although this difference was not significant $\left[F_{1}(1,13)=1.6, p>.2\right.$; $\left.F_{2}(1,33)=1.4, p>.2\right]$. 
These analyses were repeated using the subset of responses to those words for which an individual participant had responded correctly in the cued-recall task-that is, including only responses to words for which we had evidence that the participant had retained information about its new meaning. ${ }^{3}$ These analyses showed the same significance patterns as the main analysis. Participants responded significantly faster to the trained words $(M=568.2, S E=3.0)^{4}$ than to the untrained words $(M=602.2, S E=3.0)\left[F_{1}(1,13=\right.$ $\left.36.9, p<.001 ; F_{2}(1,103)=19.0, p<.001\right]$. They were also significantly more accurate for the trained words $(M=4.6 \%$, $S E=0.9)$ than for the untrained words $(M=12.1, S E=0.9)$ $\left[F_{1}(1,13)=17.1, p<.001 ; F_{2}(1,103)=8.4, p<.005\right]$. Responses were significantly faster for the related words $(M=555.3, S E=6.1)$ than for the unrelated words $(M=585.9, S E=6.1)\left[F_{1}(1,13)=5.8, p<.05 ; F_{2}(1\right.$, $33)=8.8, p<.01]$ but were nonsignificantly more accurate for the related words $(M=3.3, S E=0.9)$ than for the unrelated words $(M=5.9, S E=0.9)\left[F_{1}(1,13)=1.8, p=.2 ; F_{2}(1,33)=\right.$ $1.4, p>.2]$.

\section{Cued-recall test}

Responses were coded and analyzed in the same way as in Experiment 1. Overall, performance was better than in the previous experiments (see Table 3), but the proportion of correct responses remained higher for the related than for the unrelated items $\left[F_{1}(1,14)=16.3, p<.001 ; F_{2}(1,34)=31.6\right.$, $p<.001]$. However, there was no significant main effect of Relatedness on the numbers of properties that were recalled for these correct responses $\left[F_{1}(1,14)<1 ; F_{2}(1,34)<1\right]$. A plot of the distributions of these individual responses (Fig. 2) shows similar distributions for the related and unrelated meanings. Thus, for those word meanings that were recalled, participants were able to retrieve the same number of new semantic features, irrespective of whether these were for a word that was related or unrelated to the original meaning.

\section{General discussion}

These three experiments explored how adults learn new meanings for words that are already well established within their lexicon. Given the ubiquity of ambiguity created by acquiring new meanings for previously unambiguous words, this is an important, and yet poorly understood, aspect of adult language learning. The experiments assessed participants' ability to learn fictitious novel meanings for

\footnotetext{
${ }^{3}$ This analysis had not been possible for Experiment 2 because the lower cued-recall performance had resulted in a high level of missing data.

${ }^{4}$ Standard error adjusted to remove between-subjects variance.
}

words with a single dominant preexisting meaning. Two measures of learning were used: a cued-recall test assessing their explicit knowledge of the meanings, and a lexical decision task assessing the impact of this knowledge on online processing. We will discuss the results for these two tasks in turn.

The cued-recall task showed that recall of the new meanings was significantly better when these were semantically related to the word's preexisting meaning. In all three experiments, participants were able to correctly recall information for a higher proportion of the related meanings than for the unrelated meanings. This relatedness effect was particularly marked in Experiment 1, in which participants received only brief exposures to new meanings during incidental learning conditions and were unaware that memory would subsequently be tested. However, the relatedness effect persisted when the training phase was extended to 7 days (Exp. 2) and when semantically demanding tasks were used during training (Exp. 3). In these two experiments, the participants were aware that their memory would be tested, so we cannot be certain about the degree to which this learning reflects either incidental or intentional learning. The most likely explanation for this pervasive relatedness effect is that the semantic relationship between the old and new meanings makes it easier for participants to learn the mapping between form and meaning. Under this view, participants' primary difficulty for the unrelated meanings is not in acquiring the new meanings themselves, but in knowing which word forms they belong to. Framed in terms of connectionist models of how ambiguous words are processed (Borowsky and Masson, 1996; Joordens and Besner, 1994; Kawamoto, Farrar, \& Kello, 1994; Rodd et al. 2004), the connections between form and meaning are more easily learned for the related meanings.

An alternative locus for the relatedness effect on cued recall, which we cannot currently rule out, is that competition between the newly acquired meanings and the existing dominant meaning is increased at the time of recall for words with unrelated meanings. While the effects of relatedness on the recognition memory test used during training (Exp. 3, Worksheet 1) and the lexical decision task (Exp. 3) indicate that relatedness effects are not exclusively limited to tasks with an explicit recall component, further experiments will be needed in order to determine the extent to which meaning relatedness might separately influence the learning and recall of novel meanings.

In addition to the explicit test of participants' knowledge of the word meanings, a lexical decision task assessed whether the newly acquired meanings could affect online comprehension. In Experiments 2 and 3, participants were faster and less error-prone for the words that they had encountered during training, which likely reflects formbased repetition priming (e.g., Perea and Lupker, 2004). 
More interestingly, Experiment 3 showed a significant benefit for words whose novel meaning was semantically related to their preexisting meanings (as compared with unrelated meanings). This finding has important implications for the debate within the ambiguity-processing literature about whether and how meaning relatedness affects lexical decision performance. While several authors have reported that responses to ambiguous words with unrelated meanings are slowed relative to related meanings (Azuma and Van Orden, 1997; Beretta et al. 2005; Klepousniotou et al. 2008; Rodd, 2004; Rodd et al. 2002), other authors have reported no effect of semantic relatedness (e.g., Hino et al. 2010). These inconsistent findings might suggest that previous effects of meaning relatedness could have arisen from some other, potentially confounding difference between the particular sets of words used in the earlier experiments. Laboratory word-learning paradigms provide a useful method for ruling out alternative explanations of between-item differences on response times (e.g., for studying lexical competition; cf. Bowers et al. 2005, and Gaskell and Dumay, 2003). In the present work, we showed a significant effect of semantic relatedness on lexical decision responses using a within-item design in which the same sets of words were used (across participants) as both related and unrelated items. This finding therefore provides converging evidence that meaning relatedness plays a critical role in determining how ambiguous words are represented and processed.

What mechanism(s) underlie the semantic-relatedness effect in the lexical decision component of Experiment 3 ? First, we must rule out the possibility that this relatedness effect reflects a difference in how well these two types of words are learned. A subset analysis of Experiment 3 that only included those items for which an individual participant had learned something about the new meaning (as measured by the cued-recall task) showed a significant effect of relatedness on the lexical decision task. Importantly, for these "correctly learned" items, the results of the cued-recall task showed that participants could recall equivalent numbers of semantic properties for these two sets of items. This indicates that the semantic-relatedness effect on lexical decision performance is present even for items that are equally well learned. Instead, we propose that the relatedness effect reflects the same underlying mechanisms as the meaning relatedness effects seen for well-established ambiguous words (Beretta et al. 2005; Klepousniotou et al. 2008; Rodd, 2004; Rodd et al. 2002). These effects have been modelled within a distributed connectionist model (Rodd et al. 2004) in which recognition of words with multiple unrelated meanings is delayed by the competition between the words' mutually incompatible semantic representations, whereas recognition of words with multiple related senses is facilitated by their rich semantic representations. The present experiments cannot conclusively determine the extent to which the relatedness effect represents either facilitation from the related meaning or interference from the unrelated meaning. Future studies that include a set of baseline, unambiguous words that are presented along with their existing meanings during training may address this issue, provided that the studies ensure equal exposure to these existing meanings and to the meanings to be learned. For now, we suggest that the relatedness effect observed here reflects some combination of these two effects.

Regardless of the precise mechanisms of the relatedness effect, this result indicates that after 5 days of training using a range of semantically demanding tasks, the new meanings have become sufficiently well integrated into participants' lexicons that they can influence online recognition of these words. Interestingly, a comparable relatedness effect was not seen in the lexical decision component of Experiment 2 , which used a similar length of training (7 days) but relatively superficial rating tasks during training. We therefore speculate that a high level of semantic engagement may be a necessary requirement for participants to integrate newly acquired meanings with their existing lexical knowledge.

It may seem surprising that these newly learned meanings can influence participants' lexical decision responses to well-established, highly familiar words with a single, strongly dominant meaning (e.g., "ant" or "path"). Participants have received relatively little exposure to the novel experimental meanings, as compared with their lifetimes' experience with the preexisting dominant meanings, and reading time experiments have consistently shown that subordinate meanings have minimal impact on processing unless they are strongly supported by the sentence context (e.g., Duffy, Morris, \& Rayner, 1988). The effect is particularly striking given that participants had not encountered the new meanings since the previous day. This finding is consistent with data from recent priming experiments (Rodd et al. 2012) that have shown that participants' relative preferences for the different meanings of an ambiguous word are strongly influenced by their most recent experience with that word. Taken together, these data suggest that even strongly subordinate meanings can influence performance if they have been recently encountered (i.e., within the last day).

These effects of meaning relatedness on both explicit memory tasks and an online recognition task provide an interesting extension to the earlier lexical decision results that have shown a disadvantage for highly familiar ambiguous words whose meanings are semantically unrelated (Beretta et al. 2005; Klepousniotou et al. 2008; Rodd, 2004; Rodd et al. 2002). The results of the present 
experiments also indicate that meaning relatedness has a pervasive influence on lexical processing that emerges in the earliest stages of acquisition (Exp. 1) and continues to play a role following consolidation of new meanings (Exp. 3). We suggest that the effects of meaning relatedness on both the acquisition and the subsequent processing of ambiguous words are a consequence of a single learning mechanism that is responsible for the long-term storage of newly learned and existing words (cf. the slow neocortical learning in Davis and Gaskell, 2009). In particular, we propose that the difficulty in learning one-to-many mappings for ambiguous words with unrelated meanings that we have observed in these experiments directly results in a residual difficulty in processing these words, even when they are well established within the lexicon. This view is consistent with our distributed connectionist model of how ambiguous words are processed (Rodd et al. 2004), in which the disadvantage for processing words with multiple unrelated meanings is a direct consequence of the relatively weak connections between form and meaning that developed during training because of the inconsistent nature of the mapping (Rodd et al. 2004).

Several unanswered questions remain. First, we have not explored the impact of learning new meanings on participants' ability to recall the existing, dominant meaning. Previous work has shown that learning fictional facts about famous people can increase the time taken to verify existing (true) facts about them (Lewis and Anderson, 1976), suggesting that learning new meanings may come at a cost for the retrieval of the existing meanings, just as learning new word forms can interfere with recognition of existing forms (Gaskell and Dumay, 2003). Further work will also be needed in order to determine how recall of these newly acquired word meanings compares to recall of items without a preexisting meaning (i.e., nonwords), as well as to explore whether learning is modulated by the incidental or intentional nature of the paradigm or by participants' awareness that the meanings are fictitious. Finally, these data have potential consequences for real-world learning of ambiguous words during childhood. They suggest that learning a new word meaning might be particularly challenging for children if they already have a different, semantically unrelated meaning associated with that word. Future work across the lifespan will be needed in order to fully understand how both children and adults are able to learn such words and to determine the factors that contribute to successful learning. These data are also a useful reminder that the majority of words in language are highly ambiguous and that to fully explain how words and their meanings are learned, represented, and processed requires that we take the nature of such ambiguities into account.

\section{Appendix}

\section{Stimuli}

Trained words were used in Experiments 1-3, presented in the pairings used to creating unrelated meanings. Untrained words, nonwords, and practice/lead-in items were only used in the lexical decision task in Experiments 2 and 3.

\section{Trained words}

ant-path, bandage-fee, bone-silk, bruise-heap, cake-join, carpet-spy, carton-snake, crude-rust, foam-slot, fog-widow, grin-hive, growl-winch, pearl-crew, pouch-feast, sipdawn, slim-farm, stain-cage, stub-soup.

\section{Untrained words}

bald, barber, bee, beef, bet, blur, bold, braid, brat, breeze, brink, brown, bulk, cash, cave, cheer, chin, cork, craft, crouch, dart, deaf, exam, fake, frost, fur, fuss, gap, gate, gift, goose, grain, groom, gulp, gut, hash, haste, hood, hum, joke, Lad, lake, lion, lunch, malt, mild, parish, raid, ready, rich, ritual, rude, shack, shield, shoe, shut, skirt, slave, sled, soap, stool, surge, symptom, tall, theme, thrill, toilet, torch, trump, turf, whack, wool.

\section{Nonwords}

barr, beaf, berch, berd, blak, bloo, bom, carst, cawl, chare, cloun, cloze, coffey, craine, crie, dert, dide, doar, draip, drunck, durt, earlie, exakt, fale, fatt, ficks, flor, foks, frunt, fynd, gawl, gerl, gitar, goast, gole, graf, grean, groope, gunn, gurth, hanned, hed, hoap, horce, hugg, hye, jirk, jore, jym, kab, kap, kar, keap, kee, klean, kog, kold, krib, leest, legg, lemun, liv, lyne, maik, muffen, muther, naim, neer, nees, nite, noad, noat, nome, nurve, oan, outcide, pance, peny, peppur, poaks, polese, powk, reech, rong, rume, sadd, scid, scin, sheat, skalp, skore, smaul, sord, sto, swerl, tair, tite, tode, toun, towl, traid, trane, trea, treet, trye, wede, werld, wround.

\section{Practice/lead-in words}

bandage, bullet, elm, ethic, fame, hate, hinge, hurdle, lane, loan, lump, moan, noise, noun, orange, phrase, profit, request, rice, roof, shirt, swan, task, trot, wig, win.

\section{Practice/lead-in nonwords}

beest, burth, dedd, dreem, dum, eest, errur, fawl, flud, furst, heer, heet, kow, majur, merdge, neadle, neet, outcide, pensil, pigg, ploi, problum, roze, sye, toan, tyme. 


\section{Author note}

Experiment 3 reported here was funded by a Small Grant from the Experimental Psychology Society awarded to JMR. MHD was supported by MRC funding of the CBSU (MC-A060-5PQ80). We thank Jake Fairnie for his help in developing the paragraph materials and in conducting an earlier version of Experiment 1.

\section{Reference}

Azuma, T., \& Van Orden, G. C. (1997). Why SAFE is better than FAST: The relatedness of a word's meanings affects lexical decision times. Journal of Memory and Language, 36, 484-504. doi:10.1006/jmla.1997.2502

Balota, D. A., Yap, M. J., Cortese, M. J., Hutchison, K. A., Kessler, B., Loftis, B., . . . Treiman, R. (2007). The English Lexicon Project. Behavior Research Methods, 39, 445-459. doi:10.3758/BF03193014

Beck, I. L., McKeown, M. G., \& Kucan, L. (2002). Bringing words to life: Robust vocabulary instruction. New York, NY: Guilford Press.

Beretta, A., Fiorentino, R., \& Poeppel, D. (2005). The effects of homonymy and polysemy on lexical access: An MEG study. Cognitive Brain Research, 24, 57-65. doi:10.1016/j.cogbrainres.2004.12.006

Blank, A. (1999). Why do new meanings occur? A cognitive typology of the motivations for lexical semantic change. In A. Blank \& P. Koch (Eds.), Historical semantics and cognition (pp. 61-90). Berlin/New York: Mouton de Gruyter.

Borowsky, R., \& Masson, M. E. J. (1996). Semantic ambiguity effects in word identification. Journal of Experimental Psychology: Learning, Memory, and Cognition, 22, 63-85. doi:10.1037/ 0278-7393.22.1.63

Bowers, J. S., Davis, C. J., \& Hanley, D. A. (2005). Interfering neighbours: The impact of novel word learning on the identification of visually similar words. Cognition, 97, B45-B54. doi:10.1016/j.cognition.2005.02.002

Buckner, R. L., Bandettini, P. A., O'Craven, K. M., Savoy, R. L., Petersen, S. E., Raichle, M. E., \& Rosen, B. R. (1996). Detection of cortical activation during averaged single trials of a cognitive task using functional magnetic resonance imaging. Proceedings of the National Academy of Sciences of the United States of America, 93, 14878-14883.

Clark, H. H., \& Gerrig, R. J. (1983). Understanding old words with new meanings. Journal of Verbal Learning and Verbal Behavior, 22, 591-608. doi:10.1016/S0022-5371(83)90364-X

Davis, M. H., \& Gaskell, M. G. (2009). A complementary systems account of word learning: Neural and behavioural evidence. Philosophical Transactions of the Royal Society B, 364, 3773-3800. doi:10.1098/rstb.2009.0111

Duffy, S. A., Morris, R. K., \& Rayner, K. (1988). Lexical ambiguity and fixation times in reading. Journal of Memory and Language, 27, 429-446. doi:10.1016/0749-596X(88)90066-6

Dumay, N., \& Gaskell, M. G. (2007). Sleep-associated changes in the mental representation of spoken words. Psychological Science, 18, 35-39. doi:10.1111/j.1467-9280.2007.01845.x

Fellbaum, C. (1998). WordNet: An Electronic Lexical Database. Cambridge, MA: MIT Press.

Frisson, S., \& Pickering, M. J. (2007). The processing of familiar and novel senses of a word: Why reading Dickens is easy but reading Needham can be hard. Language and Cognitive Processes, 22, 595-613. doi:10.1080/01690960601017013

Gaskell, M. G., \& Dumay, N. (2003). Lexical competition and the acquisition of novel words. Cognition, 89, 105-132. doi:10.1016/ S0010-0277(03)00070-2
Hino, Y., Kusunose, Y., \& Lupker, S. J. (2010). The relatedness-ofmeaning effect for ambiguous words in lexical-decision tasks: When does relatedness matter? Canadian Journal of Experimental Psychology, 64, 180-196. doi:10.1037/a0020475

Joordens, S., \& Besner, D. (1994). When banking on meaning is not (yet) money in the bank: Explorations in connectionist modeling. Journal of Experimental Psychology: Learning, Memory, and Cognition, 20, 1051-1062. doi:10.1037/02787393.20.5.1051

Kawamoto, A. H., Farrar, W. T., \& Kello, C. T. (1994). When two meanings are better than one: Modeling the ambiguity advantage using a recurrent distributed network. Journal of Experimental Psychology: Human Perception and Performance, 20, 12331247. doi:10.1037/0096-1523.20.6.1233

Klepousniotou, E., Titone, D., \& Romero, C. (2008). Making sense of word senses: The comprehension of polysemy depends on sense overlap. Journal of Experimental Psychology: Learning, Memory, and Cognition, 34, 1534-1543. doi: $10.1037 / \mathrm{a} 0013012$

Leach, L., \& Samuel, A. G. (2007). Lexical configuration and lexical engagement: When adults learn new words. Cognitive Psychology, 55, 306-353. doi:10.1016/j.cogpsych.2007.01.001

Lewis, C. H., \& Anderson, J. R. (1976). Interference with real world knowledge. Cognitive Psychology, 8, 311-335. doi:10.1016/ 0010-0285(76)90010-4

Lupker, S. J. (2007). Representation and processing of lexically ambiguous words. In M. G. Gaskell (Ed.), The Oxford handbook of psycholinguistics (pp. 159-174). Oxford, U.K.: Oxford University Press.

Parks, R., Ray, J., \& Bland, S. (1998). Wordsmyth English DictionaryThesaurus [Electronic version]. Chicago, IL: University of Chicago. Retrieved from www.wordsmyth.net

Perea, M., \& Lupker, S. J. (2004). Can CANISO activate CASINO? Transposed-letter similarity effects with nonadjacent letter positions. Journal of Memory and Language, 51, 231-246. doi:10.1016/j.jml.2004.05.005

Pollatsek, A., \& Well, A. D. (1995). On the use of counterbalanced designs in cognitive research: a suggestion for a better and more powerful analysis. Journal of Experimental Psychology: Learning, Memory, and Cognition, 21, 785-794. doi:10.1037/02787393.21 .3 .785

Raven, J., Raven, J. C., \& Court, J. H. (1998). Manual for Raven's Progressive Matrices and Vocabulary Scales: Section 5. The Mill Hill Vocabulary Scale. San Antonio, TX.: Harcourt Assessment.

Rodd, J. M. (2001). Semantic representation and lexical competition: Evidence from ambiguity (Unpublished Ph.D. thesis). University of Cambridge, Cambridge, U.K.

Rodd, J. M. (2004). The effect of semantic ambiguity on reading aloud: A twist in the tale. Psychonomic Bulletin \& Review, 11, 440-445. doi:10.3758/BF03196592

Rodd, J., Gaskell, G., \& Marslen-Wilson, W. (2002). Making sense of semantic ambiguity: Semantic competition in lexical access. Journal of Memory and Language, 46, 245-266. doi:10.1006/ jmla.2001.2810

Rodd, J. M., Gaskell, M. G., \& Marslen-Wilson, W. D. (2004). Modelling the effects of semantic ambiguity in word recognition. Cognitive Science, 28, 89-104. doi:10.1207/s15516709cog2801_4

Rodd, J.M., Lopez Cutrin, M.B., Millar, A., \& Davis, M.H. (2011) Learning about the meanings of ambiguous words: The influences of recent and long-term experience. Meeting of the Experimental Psychology Society (EPS). Oxford, 13-15, April 2011.

Schneider, W., Eschman, A., \& Zuccolotto, A. (2002). E-Prime user's guide. Pittsburgh, PA.: Psychology Software Tools, Inc. 